\title{
ATIVIDADES AVALIATIVAS NA EDUCAÇÃO A DISTÂNCIA: POSSIBILIDADES E LIMITES DOS RECURSOS NO MOODLE
}

TAUBATÉ/SP ABRIL/2018

\author{
Jeniffer de Souza Faria - EPTS - jeniffersouza05@gmail.com \\ Josimary de Oliveira Pinto_ - EPTS - josimary_oliveira@yahoo.com.br \\ Rosana Salles Raymundo－EPTS - rosalles2011@hotmail.com
}

Tipo: Relato de Experiência Inovadora (EI)

Categoria: Pesquisa e Avaliação

Setor Educacional: EDUCAÇÃO SUPERIOR

\begin{abstract}
RESUMO
O presente texto tem por objetivo problematizar o uso de alguns recursos disponibilizados especificamente na plataforma Moodle, apontando para diferentes possibilidades de atividades avaliativas complementares utilizadas nos cursos a distância, bem como seus limites. Como recurso metodológico, utilizamos da revisão de literatura articulada as experiências profissionais como tutor de cursos a distância. Apesar das diferentes possibilidades que estas ferramentas oferecem, percebemos seu uso de forma limitada, assim como a estrita relação com o plágio nos trabalhos acadêmicos. Portanto, se faz necessário compreender as possibilidades de algumas ferramentas para, de alguma forma, incentivar que elas proporcionem atividades significativas, cooperativas, autônomas e críticas. Como resultado de nossas reflexões percebe-se que se faz necessário repensar as estratégias para acompanhamento do processo de avaliação da aprendizagem por meio dos diferentes recursos/atividades disponíveis pelas Tecnologias de Comunicação e Informação e pelo AVA para que sejam verdadeiramente capazes de alcançar os propósitos educacionais ensejados pelos responsáveis do processo formativo.
\end{abstract}

Palavras-chave: Educação a Distância. Ambiente Virtual de Aprendizagem. Recursos. Avaliação.

\section{AGRADECIMENTOS}

NÃO HÁ. 


\section{Introdução}

A emergência de inovação na formação profissional de professores é uma exigência cada vez mais presente nas universidades frente aos avanços científicos e tecnológicos, à globalização, à mudança de processos de produção e suas consequências na educação, dentre outros aspectos. Nesse contexto, podemos apontar como uma significativa mudança no sistema universitário a oferta de cursos a distância que articulam o uso de tecnologias no processo formativo.

Apesar da clareza quanto à necessidade de mudanças e de atender às demandas atuais o movimento apresenta antigos problemas, também encontrados no ensino presencial, os quais precisam ser desvelados, analisados, compreendidos e, quiçá, superados. Dentre eles, procuraremos refletir neste artigo sobre as atividades avaliativas propostas em cursos superiores a distância a partir dos recursos disponíveis no Moodle, procurando apontar para diferentes possibilidades, bem como seus limites.

Entretanto, de forma antecedente se faz necessário refletir sobre alguns aspectos relacionados ao processo de avaliação e sua relação com a qualidade da Educação para posteriormente emergir considerações sobre, pelo menos, três recurso disponível no Ambiente Virtual de Aprendizagem (AVA) mais utilizados em nossa prática educativa.

\section{Apontamentos sobre avaliação na EaD e qualidade na Educação}

Avaliar (do latim valere, quer dizer ter saúde, ser forte, ter valor) significa reconhecer a valia, atribuir valor ou significado. No senso comum, avaliar é atribuir valor a um objeto. (VASCONCELLOS, 1998, p. 84 apud FRANÇA, 2012, p.41).

Definir avaliação é algo complexo, pois este termo admite diferentes significados, como verificar, medir, classificar, diagnosticar entre outros, conforme nos aponta Vasconcelos (1998 apud FRANÇA, 2012). No âmbito educativo podemos dizer que a avaliação extrapola a função de medida, verificação, atribuição de valor em razão da sua intencionalidade e do seu potencial transformador.

Ainda de acordo com Vasconcellos (1998 apud FRANÇA, 2012) a finalidade da avaliação é a captação de necessidades, e esta captação é feita a partir do confronto entre a situação atual e a situação desejada, visando uma intervenção na realidade para favorecer a aproximação entre ambas. Avaliar é ser capaz de acompanhar o processo de construção do conhecimento do educando, para ajudar a superar obstáculos. (VASCONCELLOS, 1998, p. 85 apud FRANÇA, 2012, p. 43). 
Frente a estas reflexões, podemos inferir que a avaliação da aprendizagem se coloca como um acompanhamento sistemático do processo de ensino, que acontece por meio de procedimentos como a "observação, registro, análise, comunicação e tomada de decisão em função da transformação da realidade" (FRANÇA, 2012, p. 43). Portanto, é diferente de ensinar e cobrar um produto ao final do processo para conferir se o que se pretendia foi alcançado ou não, como um parâmetro.

Nesse contexto, avaliar se coloca como uma ação necessária e indispensável à condição humana para nortear aquilo que se deve fazer. Entretanto, vale ressaltar que a avaliação possui um caráter dinâmico e subjetivo, ou seja, que o cotidiano dos avaliadores e avaliados estão associados no processo avaliativo, e ambos se colocam "com todos os seus anseios e sentimentos, com a sua capacidade intelectual e cognitiva, suas paixões, expectativas, sonhos, ideias e ideologias", ou seja, os sujeitos se colocam sob influência das relações sociais, crenças, valores, concepções, que estabeleceram ao longo da vida. (FRANÇA, 2012)

Logo, se levarmos este saber em consideração, no processo de avaliação não seria cabível ter uma "concepção e a prática de avaliação que privilegia a visão parcial, fragmentada ou cristalizada sobre a aprendizagem do aluno" (FRANÇA, 2012, p. 45).

Na perspectiva de França (2012, p.45), ao considerar que a sala de aula ou qualquer ambiente de aprendizagem se apresentam como ricos espaços de interação, "trocas de saberes e construção do conhecimento, mas também de tensões, conflitos e contradições" o professor não pode conceber este espaço como "lugar de respostas prontas e do conhecimento absolutizado". Em suas palavras, "é no mínimo impróprio entendê-la [a sala de aula] como o momento de verificação do aprendizado do aluno por meio da aplicação de provas pontuais de cujos resultados se extraem as médias e se definem as classificações dos alunos e seus destinos na escola e na sociedade." (FRANÇA, 2012, p. 46)

Portanto, podemos inferir que não se faz uma educação de qualidade, independente do nível ou modalidade de ensino, sem uma prática efetiva de avaliação, e essa premissa não é distinta nos cursos a distância. Entretanto, se faz necessário considerar que a avaliação possibilita uma visão holística do processo educativo e sua eficiência nos ambientes virtuais de aprendizagem (AVA) depende da utilização adequada das ferramentas avaliativas em consonância com os aspectos conceituais e procedimentais do ato de avaliar.

\section{Metodologia}


Para a elaboração deste relato pautamos nas premissas metodológicas da revisão de literatura articulada a um estudo descritivo a partir das experiências profissionais como tutor de cursos a distância que utilizam a plataforma Moodle como Ambiente Virtual de Aprendizagem, uma vez que tivemos como objetivo descrever as características de um fenômeno ou problema (uso dos recursos do AVA) procurando conhecer e analisar as principais contribuições teóricas existentes sobre ele.

\section{O Ambiente Virtual de Aprendizagem e seus recursos}

As atividades avaliativas são componentes obrigatórios e essenciais para a aprovação do aluno em qualquer processo formativo. Na modalidade a distância não poderia ser diferente e, por isso, alguns recursos são acoplados aos Ambientes Virtuais de Aprendizagem (AVA), os quais se constituem como uma das principais ferramentas da Educação a Distância (EaD) para desenvolver o trabalho formativo, que se desenvolve no e com este ambiente.

De acordo com Silva et al (2014) os AVA provocaram mudanças e reflexões positivas sobre o processo educacional como um todo, pois estes permitem outras e novas possibilidades pedagógicas, "espaços" para promover a aprendizagem e a dialogicidade por meio dos seus diversos recursos que permitem interação, comunicação, divulgação do conhecimento e também avaliar.

Nesse contexto, podemos observar que o cumprimento das atividades propostas nos AVA é o que sinaliza a participação discente e, por conta disso, se constitui um desafio aos produtores de conteúdo na EaD diminuir a escassez e o uso mecânico dos recursos. Atentamos para a necessidade de incorporar no processo formativo as tecnologias e propor formas cooperativas e/ou colaborativas, pois nem sempre os que pensam o formato do curso buscam alternativas para superar esta perspectiva restrita. (SILVA et al, 2014).

Dentro desta perspectiva, das possibilidades que o Moodle oferece e do limite deste artigo, passamos a descrever de forma reflexiva os limites e as possibilidades sobre alguns dos recursos mais utilizados em nossa prática: Fórum, Questionário e Tarefa.

De acordo com sua denominação o Fórum de discussão"permite aos participantes realizar discussões assíncronas", ou seja, comunicação não simultânea, na medida em que a postagem de mensagem é feita pelos participantes em momentos diferentes. (BRAGA, 2013, p. 92). 
Para Xavier e Santos (2005 apud DIAS; LEITE, 2014, p. 107) o objetivo desta atividade continua sendo inspirado pelo gênero fórum antes da sociedade tecnológica, o qual "consistia na discussão de problemas específicos em comunidades civis e institucionais, a fim de, pela exposição de opiniões diversas em um amplo debate, encontrar coletivamente mecanismos e estratégias de solução" de forma democrática.

Para alcançar este objetivo, geralmente, o fórum possui uma informação inicial contextualizada que instiga a discussão. Dentre as possibilidades podemos ter questões pautadas em filmes, textos de diferentes gêneros, ideias que buscam complementos, problematizações que buscam soluções, dentre outros que permitam, sobretudo, 0 diálogo.

Desse modo, esta ferramenta se coloca como "um meio, um instrumento, não um fim, e, obviamente, com grandes possibilidades de interação", pois favorece aprendizagem colaborativa e permite a apresentação de diferentes pontos de vista sobre um mesmo tema. Vale ressaltar que cabe ao professor/tutor, no decorrer do processo de discussão, publicar mensagens que resumem os principais aspectos apresentados pelos alunos, "minimizando os riscos de fragmentação". (DIAS; LEITE, 2014, p. 108).

Entretanto, percebe-se que não é comum requerer dos participantes postagens utilizando outras linguagens como imagens ou desenhos, indicação de filmes, proposição de questões, relato de experiências, ou seja, não há versatilidade na forma como o aluno pode participar, mas apenas nas formas que o fórum pode ser organizado.

Assim, a produção de texto (opinião ou síntese) é unânime e nem sempre o diálogo acontece. Nesse contexto, devemos tomar cuidado para que esta ferramenta não corrobore com a participação isolada - fato observável em turmas com diferentes quantidades de alunos ( 1 a 100) e que nos faz questionar se cabe a este recurso limitar o número de participantes para que possa acontecer uma efetiva interação ou discussão entre alunos e entre alunos e professor. Isso geralmente acontece quando são elaboradas perguntas para o fórum que requerem apresentação de conteúdo estudado, o aluno então responde ao que foi perguntado e não há como outros participantes interagirem com sua postagem, pois não há margem para interpretações ou diálogo.

Outro ponto negativo que podemos observar é a dificuldade na interpretação do propósito do fórum e o gênero textual que deve ser utilizado pelo aluno para demonstrar sua "participação". Tanto no que diz respeito ao quesito interpretação quanto ao gênero textual adequado, os problemas são confirmados pelo fato de haver nos comentários trechos de textos publicados (independente da fonte), ou seja, que não foi elaborado 
pelo aluno. O fórum, independente do formato, é um espaço para comentários pessoais, impressões, observações, sínteses, diálogo e não reprodução de textos consolidados. É uma ferramenta que permite ou pelo menos deveria permitir livre expressão dos participantes sobre diferentes pontos de vistas, instigar o bom senso, diálogo, coerência e objetividade.

Frente ao exposto concluímos que o Fórum é uma ferramenta essencial para quem quer exercer prática de autoria e tutoria em cursos a distância, e adequada para realização de atividades sócio-interacionais, trabalhos colaborativos, debates, entre outras atividades coletivas que podem ou não ser avaliativas, ou seja, ter atribuição de nota. Vale ressaltar que apesar da possibilidade avaliativa dos fóruns, acreditamos que pelos objetivos e possibilidades descritas desta ferramenta deve-se evitar este procedimento. Afinal, há outras atividades que realizam este procedimento de forma mais eficaz, como por exemplo, o questionário.

Esta atividade se faz presente em alguns cursos, principalmente como uma forma de avaliação para aqueles que possuem um número significativo de alunos. Este recurso possui uma lógica específica, pois não é interativo e pode ser autocorrigido quando organizado em questões objetivas, informando automaticamente ao aluno e tutor sobre os resultados obtidos.

Dito isso, esta possibilidade de autocorreção dá credibilidade a esta ferramenta como recurso avaliativo e apesar de serem organizadas majoritariamente com questões objetivas há espaço para inserir questões subjetivas curtas e dissertativas, possibilitando ao professor explorar diferentes estilos de aprendizagem dos alunos. (DIAS; LEITE, 2014)

Dentre as possibilidades de organização do questionário temos: indicação de verdadeiro ou falso; múltipla escolha, em que há apenas uma resposta correta; associação, na qual o aluno deverá relacionar os itens entre duas colunas; resposta breve, em que para estar correto o aluno deve apresentar uma resposta objetiva (uma palavra, por exemplo); resposta numérica, em que o aluno responde uma questão que envolve cálculo e cujos dados são fixos. Vale dizer que ainda há nesta atividade a possibilidade de inserir limite de tempo para respondê-lo e de organizá-lo possibilitando diferentes formas de visualização.

Ao submeter o estudante a um questionário entende-se que ele precisa se preparar, ou seja, ter adquirido conhecimento por meio da leitura do conteúdo que será avaliado. Logo tutor/professor e aluno têm um feedback preciso sobre o conhecimento adquirido e 
do que ainda não foi consolidado ou gerou dúvida. Após a conclusão do questionário o tutor pode discutir com o aluno sobre suas respostas em outra ferramenta como o fórum, mensagem ou chat.

Por fim, dentro dos limites deste texto, tratamos do recurso Tarefa.De modo geral elas servem para enviar arquivos para o ambiente e estes podem estar em diferentes formatos (Word, PDF, JPEG, etc.). Nesta opção a produção pode ocorrer off-line, ou seja, fora da plataforma, além de ser realizada individualmente ou em pares e ser enviada após sua conclusão. (DIAS; LEITE, 2014)

Outra possibilidade dentro desta mesma atividade é a produção de texto online. Nesta configuração, para realizar a tarefa, o aluno precisa redigir seu texto no editor do Moodle, ou seja, há um espaço dentro da própria plataforma em que o aluno registra sua produção textual e posteriormente envia para ser avaliada. Uma vantagem desta ferramenta é não necessitar de um programa, como editores de texto e ser ideal para atividades que requerem uma produção curta e sem imagens.

A principal função desta ferramenta, independente do formato, é organizar a entrega de trabalhos pelos alunos, os quais somente ele e o professor/tutor têm acesso, garantindo a privacidade da publicação tanto da produção quanto da avaliação atribuída para cada um.

Ressaltamos que para otimizar a utilização deste recurso pode-se disponibilizar um modelo de página com as informações e configurações desejáveis. Este procedimento instiga o aluno a elaborar uma atividade mais organizada, além de aprender as configurações básicas de um editor de texto como, por exemplo, o Word.

Frente a esta descrição, não há como negar que a ferramenta Tarefa consista em uma boa atividade para avaliar, principalmente quando uma produção de texto é solicitada ou quando há mais de uma questão a ser respondida. Há apenas que se atentar ao fato de que se na elaboração da questão deixar-se margem para a inclusão de imagens e/ou tabelas no corpo da Tarefa, o tipo de entrega deve ser disponibilizado como "Envio de arquivo" e não apenas "texto online". Este detalhe é importante ser pensado durante a elaboração do enunciado da atividade para que seja informado, de forma clara, ao aluno. Caso contrário poderão elaborar um tipo de atividade que não terá condições de ser anexada por completo no AVA.

Em linhas gerais, os recursos que existem na plataforma Moodle ou em outras ou fora do AVA podem e devem ser utilizados de forma criativa, desconstruindo a ideia de um 
ambiente como repositório de conteúdos e tarefas como mera formalidade, que permita a autoria da resposta pelos alunos, que efetivamente os avaliem naquilo que conseguiram apreender com os conteúdos dispostos, evitando assim dar margem para uma simples cópia de uma resposta "pronta", pois corremos o risco de formar alunos meros executores de tarefas - numa perspectiva micro, inicialmente, para ser aprovado em uma disciplina e numa perspectiva macro, posteriormente, para obter o título. (BRAGA, 2013)

Para finalizarmos, salientamos que frente à recente necessidade metodológica de instituir diferentes modos de construção de conhecimento, principalmente em grupos (aprendizagem colaborativa), e dos alunos desenvolverem formas mais autônomas de estudo (aprendizagem reflexiva e auto monitorada) entendemos que se faz urgente a capacitação de professores para utilizar as ferramentas no ambiente digital em consonância com as especificidades da educação a distância e do perfil de alunos que ela atende.

\section{Algumas Considerações}

O primeiro ponto que constatamos neste trabalho é que não foram abordados de forma mais profunda, aspectos relacionados a avaliação presencial, ato obrigatório na EaD, pois caberia a escrita de outro(s) texto(s).

Por outro lado, procuramos dar visibilidade aos recursos/atividades que os Ambientes Virtuais de Aprendizagem oferecem, como forma de complementação da avaliação dos alunos nos cursos a distância no ensino superior. Dentre os instrumentos que foram abordados neste texto apontamos o Questionário, a Tarefa e o Fórum como recursos que ora apresentam potencialidades avaliativas e ora comunicativas, como o Fórum. A nosso ver, esta ferramenta se constitui melhor recurso para promover a interação, aproximação entre os participantes imersos nas plataformas que oferecem educação a distância.

Nesse sentido, podemos inferir que apesar de cada ferramenta ter sido criada com um determinado objetivo, a partir da criatividade dos que pensam e fazem a EaD é possível implementar significativas variações de uso. Pensar sobre isso significa melhorar qualitativamente as formas de avaliação que se tem colocado nas atividades propostas nos cursos de licenciatura a distância e propor uma reflexão sobre a própria didática dos conteúdos abordados nas disciplinas pedagógicas e específicas.

Além disso, os professores/tutores precisam ter a oportunidade de conhecer 
criticamente e utilizar tais recursos rompendo o senso comum de que este profissional possui dificuldade ou não faz uso diferenciado dos recursos, em sua prática pedagógica, por não conhecê-lo.

Frente a estas colocações ressaltamos que as ferramentas podem e devem ser aproveitadas de diferentes formas para o mesmo objetivo ou outro, pois não há dúvida de que é possível fomentar reflexões e discussões por meio dos recursos/atividades que - AVA oferece, entretanto ainda é escasso o uso de diferentes linguagens ou qualquer outra estratégia que seja capaz de promover dinâmicas de aprendizagem mais significativas.

Portanto, incitamos ser necessário repensar as estratégias para acompanhamento do processo de avaliação da aprendizagem por meio dos diferentes recursos/atividades disponíveis pelas Tecnologias de Comunicação e Informação e pelo AVA para que sejam verdadeiramente capazes de alcançar os propósitos educacionais ensejados pelos responsáveis do processo formativo.

\section{Referências}

BRAGA, Denise B. Ambientes digitais: reflexões teóricas e práticas. São Paulo: Cortez, 2013.

DIAS, Rosilâna A., LEITE, Lígia S. Educação a distância: da legislação ao pedagógico. $4^{a}$ ed. Petrópolis: Vozes, 2014.

FRANÇA, Odila A. V. Planejamento Educacional e Avaliação Escolar. Taubaté: Unitau, 2012.

SILVA, Danilo G. da et al. Um olhar interno pra os recursos do Moodle: algumas considerações sobre participação e interação. In: Reali Al, M. de M.R \& Mill, Daniel. Educação a distância e tecnologias digitais: reflexões sobre sujeitos, saberes, contextos e processos. São Carlos: EdUFSCar, 2014. 